\title{
Tourism Destination Management: A Collaborative Approach
}

\author{
Salvatore Ammirato, Alberto Michele Felicetti, and Marco Della Gala \\ Department of Mechanical, Energy and Management Engineering, University of Calabria, \\ via P. Bucci, 42lC, 87036 Rende (CS), Italy \\ \{salvatore.ammirato, alberto.felicetti, marco.dellagala\}@unical.it
}

\begin{abstract}
Collaboration is a key factor of sustainable growth across territories and industrial sectors. Tourism, one of the largest industries in the world, has been subject to strongest innovation in the last years. Main reasons of this reside both in the availability of new ICTs - Information and Communication Technologies - and organizational models, which directly connect tourists among them and with service providers, and in the always more personalized supply of tourism experience. Tourism destinations can benefit of such innovations if they are able to reorganize the territorial tourism offer around different pattern of collaboration in order to give 2.0 tourists opportunities to live an augmented tourism experience. This paper deals with the possible forms of collaborative networks that can rise within a destination with a focus on relationships between services delivered by the Tourism Destination and the requests of services at the different phases of the tourist 2.0 lifecycle.
\end{abstract}

Keywords: Tourism breeding environment, Collaborative Networked Organization, Tourism Extended Enterprise, Tourism Virtual Organization, augmented tourism experience, tourist 2.0 lifecycle.

\section{Introduction}

Last decades were characterized by a growing interest toward tourism sector due to its increasing impact to the economic development of many countries [1].

Anyway, not all tourism destinations over the world are able to benefit of the tourism industry development. Nowadays, even the traditional tourism destinations are invested by the current financial and economic downturn experimenting the discharge from the tourists' preferred destinations at global level [2].

The traditional development model, based on an outdated tourism supply chain model, appears inadequate and unsustainable to support tourism destinations in the strong and globalized competition [3]

As argued in [4], in recent years the tastes of tourists have changed and the numbers of tourists in search of "something different" from mass tourism is growing. Culture and people thus become part of the tourism product; competition is always more based on offering tourists articulate packages composed by different services (hotel, restaurant, nature, visits to cultural heritage, sports, handicrafts, etc.) that, all together, enable tourists experience a territory as a whole [5] [6] [7]. 
In this context, the accelerating and synergistic interaction between the ICTs and tourism brought extensive transformation of the industry itself, gradually generating a new paradigm-shift. The ICT is changing the tourism industry structure providing a whole range of opportunities for all stakeholders; it is widely recognized that ICT alter barriers to entry, revolutions distribution channels, as well empowers consumers to identify, customize and purchase tourism products [8] [9].

The depicted industry evolution shows new potentials for local service providers usually marginalized from main tourism flows, due to their small sizes, and unable to compete in the globalized market. In many regions characterized by niche tourism vocation (e.g.: historical, business, sport, cultural, rural, religious etc.), or localized in developing countries, or simply where some organizations decided to create "alternative" development paths, local tourism operators have started organizing themselves spontaneously in "Collaborative Networks", CNs. The main objective of such CNs is to create aggregate tourism offers able to compete with big tourism operators thus transforming regions with potential and vocation in real tourism destinations. At the same time, tourists have the opportunity to experiencing a good holyday respecting the local place and people.

The aim of this paper is to describe how the organizational paradigm of collaborative networks applied to the tourism sector, when correctly managed and supported by ICTs, can be the right means for the sustainable development of local areas. The paper is structured as follows. In section 2 , a characterization of a tourism destination, highlighting the key factors for its development in contrast with the traditional supply chain, is proposed, reporting also main advantages for adopting a $\mathrm{CN}$ model for the tourism destination management. In section 3, the concept of the tourism 2.0 lifecycle is introduced, related to the tourist's needs for an augmented tourism experience, giving the motivations why the adoption of a $\mathrm{CN}$ model is an effective way to answer the tourist's needs. Section 4 reports the operationalization of the concept of $\mathrm{CN}$ in tourism. Conclusions of the study are reported in section 5.

\section{Characterizing a Tourism Destination}

The presence of attraction factors (both physical elements, like natural resources and monuments, and social factors, like the language spoken and friendliness of the local people), although a necessary condition, is not enough for turning a territory in a tourism destination [10], [11]. The key factor for the rise and continuous development of a tourism destination resides in the quality and efficacy of relations among service providers and between them and the destination's environment. Effective relations can give the tourism destination the basis for agility in dynamic and turbulent market conditions. Offering to an always more demanding tourist an integral, flexible and personal experience, as a result of the interactions among specialized service providers, can be a winning strategy for the tourism destination to gain sustainable development and emerge in the global competition.

In a tourism destination, live and operate different autonomous entities (people and organizations) whose business is related to the sector. While these entities can be heterogeneous in terms of their operating environment, culture, social capital and goals, they all aim to achieve the common goal of tourism destination development 
and to increase the general competitiveness respect to other geographical areas within the global competition. We define these entities as tourism service providers that can be grouped into the following categories [5]:

- Hospitality Services Enterprises: companies that offer overnight accommodation (e.g. hotels, B\&B) and meal provision (e.g. restaurant).

- Transportation Services providers: public and private companies that provide services of people transportation (i.e. buses, taxies, airplanes, trains, etc).

- Event Management Services: public and private companies dealing with the organization of events (e.g.: conferences, conventions, concerts, sport events).

- Tourism complementary goods and services providers: companies that produce and offer complementary goods and services for travelers, like local shops, museums, excursion services, sport \& leisure facilities, handicrafts.

Although the tourism service providers interact at different levels, from the commercial to the operational one, they all collaborate to develop the tourism destination in the forms of both partnership agreements and informal relations. Their aim is to deliver a competitive offer of tourism services. Interactions among service providers model the set of all services characterizing the tourism destination.

From the set of relations within a tourism destination results the tourism supply chain whose success depends from the way it is managed.

Actually, the real obstacle for the sustainable development of the tourism destinations is that the tourism supply chain control remains in the big companies charged to market the destination (generally, the international tour operators). Big tourism corporations control almost every services selling among disconnected operators and tourists through complex supply chains. A typical example is the tourist village model, where all the services are provided by the village owner, often a big not-local company whose aim is only the fast return on investment with all the consequences for the local socio-economic and natural environment. Consequences of the traditional tourism supply chain control's model, reside in territory saturation, environmental degradation, stress on infrastructures, in the loss of bargaining power for local service providers, and, with time, the deterioration of the services provided.

As tourism service providers become a part of the global economy, local collaborative actions that generate externalities for the companies increase in importance. Engaging in new forms of collaboration and promoting and maintaining relationships within business networks have become a natural way for organizations to meet increasing flexibility and performance requirements in competitive markets [12]. Reduced cost and investments, improved efficiency, scale and scope economies are further motivations for local players in engaging collaborative actions within the industry.

In the tourism sector, the supply chain management is moving from a centralized task of the majority chain shareholder to a collective responsibility among channel partners. Models of CNs in the tourism sector are characterized by a direct connection among local service providers and tourists with these explicit ethical and political goals: re-vitalisation of territory identity and local community relations to local natural, cultural and historical heritage, linking with sustainable agriculture and handicraft, economically viable and socially responsible practices [13]. In other words, the traditional and centralized supply chain model, based on the overexploitation of the destination's resources, is always more turning in a collaborative and sustainable one. 
Scholars tried to deepen the understanding of the $\mathrm{CN}$ in tourism phenomenon proposing theories and identifying successful case studies of "alternative" tourism supply chain showing how collective intelligence of the members is appropriated to ensemble innovative information-based products for tourists, highlighting how a common vision among all stakeholders is mandatory to protect the resources and the importance of a collaborative approach in the marketing of the destination [14].

\section{The Tourist 2.0 Lifecycle and the Augmented Tourism Experience}

In the effort to deepen the tourism experience from the tourist point of view, scholars introduced the concept of the tourism experience lifecycle [15]. A diffused approach in defining it consists in adapting generic models to describe consumer behavior in purchasing products or services [16]. Other scholars, suggested that travel is a "linear" process, defined the touristic experience from a temporal perspective which involves three phases: the anticipatory phase; the experiential phase; and the reflective phase [17]. Unfortunately, according to Swarbrooke and Horner [16], there are several reasons why most of previous models are no longer adequate to describe the process of tourism today. The main problem seems to be that previous models are dated and do not fit to the present scenario in which the use of Internet has dramatically changed the ICT use and the consumer behavior.

The Internet technologies, by the providing of sharing, context aware and automation services radically changed the meaning of mediation in tourism context: not only tourists get connected in a anticipatory way with destinations through web media contents, but they become more and more autonomous in decision-making processes, disintermediating players of tourism market, such as travel agencies and tour operators, and exploiting the customer insights and reviews, provided by people through social media.

The availability of networking ICTs allowed the rise and diffusion of $\mathrm{CN}$ models all around the world by enabling operators to develop original ways to manage the tourism supply chains, the destination marketing and relations with customers.

From a tourist perspective, ICT provides services able to help the decision making process. The possibility to taste in advance a trip (thanks to videos, photos, opinions and storytelling of other users), the opportunity to compare thousands of offers through fare aggregators and meta search engines, the immediate delivery of a set of tourism services (e.g. reservation or booking, payment, etc...) are among the features that make the Internet\&tourism an absolutely winning combination. The emergence of social networking platforms have further influenced the whole tourist experience lifecycle by the mean of the new ways tourist interact with peers. Moreover mobile technologies have challenged today's tourists expectations getting personalized access to tourism information at any time, from anywhere with any media, creating a paradigm shift in how information is accessed and digested, and transactions performed [18].

Demand and supply of ICTs have innovated considerably the sector in operational workflows, management and marketing of tourism packages and in new paradigms of tourism experiences 
We can name this paradigm shift as augmented tourism experience. To be effective and competitive on the market, a tourism destination needs to deliver information services for matching necessities of each phase of the tourist 2.0 life cycle in the effort to offer tourists an augmented tourism experience.

In the effort to clarify how ICTs have reengineered the tourism experience, we need to analyze how ICT provides specific contents and automates the activities typically carried out by a tourist.

In what follows, we propose the tourist 2.0 lifecycle i.e. a model of tourism experience that fits the modern consumption paradigm of tourism products/services.

The model consists of the following phases:

Dreaming: The process begins with the emergence of a need, a desire to travel. In this phase, tourists look for inspiration for their vacation. While in the past, most of the ideas came from photos, stories and memories of friends' past experiences or brochures of Travel Agencies (TAs) or Tour Operators (TOs), today the internet greatly simplifies this step. The dream of holiday is fed by an overabundance of photos, videos, or maps on the web, allowing users to gain virtual previews of the holiday, explore places, identify the location, refer to opinions and recommendations published by travelers who already had an experience and then prospected tourists begin to "dream" their vacation. In this direction goes a category of ICT services that could be delivered by "inspiration portals", like Tripfilms.com, Panoramio.com, Pinterest.com, Facebook.com etc., which provide the opportunity of sharing geotagged multimedia content among users by allowing them to get a preview of the territories, cultures and type of vacation.

Planning \& Booking: Once the tourist identifies the potential destination and the type of holiday he intends to do, he proceeds with the detailed planning of the trip. After establishing the details of the whole holiday, all that remains before travel is to make reservations of transportation, accommodation and any additional services (car rental, excursions, events, etc.) that will complete the tourism package. Until a few years ago, planning and booking activities were generally carried out by TAs and TOs, who had to book transportation, accommodations, and activities or to create complete packages for the customer whose only concern was to pay the broker.

Nowadays the availability of web services based on comparison, recommendation systems, and booking services like booking.com, trivago.com, e-dreams.com, expedia.com, etc., leads consumers to make self-service reservations with increasing frequency, allowing them to enjoy lower costs related to the absence of intermediaries, to book at any time from everywhere.

Experiencing: This phase is mainly related with the in-place tourism activities: the tourist overnight stays in hotels, make excursions, enjoy meals, visit local attractions etc.. The main difference with the past at this stage is the availability of contextualized information and additional services (maps, location-based services, context-aware mobile tourism guides, augmented reality etc..) offered to the tourist 2.0 through mobile devices as well as the opportunity to share location-based multimedia contents through web-services like Foursquare.com, Facebook Places, Loopt.com, etc.. Examples of context-aware mobile tourism applications are mTrip guides, myTrip, Tripadvisor, that provide contextualized information and services to produce more focused and useful recommendations to the user. Based on location, 
user profile (preferences), time, and pre-stored trip information, a user get recommendations about points of interest, plan personalized tours, get informed on nearby restaurant opening times, be advised where to eat on the basis of his food preferences, get public transport information, etc. [18]

Recollecting: After experiencing the holiday, the tourist comes back home and remembers the experience through photo albums, souvenirs and storytelling. At this phase of the tourism 2.0 lifecycle, the main ICT tools are those based on sharing services, as in the dreaming phase. The meaning of using specialized portals to share photos, videos, stories and opinions on visited places is to collect some snapshot of the vacation in order to recall its memory and to give tips and advices on the experienced tourism destination.

\section{CNs Model to Deliver a Competitive Augmented Tourism Experience in a Tourism Destination}

An extensive literature recognizes benefits deriving from $\mathrm{CN}$ agreements both from partner organizations and customers. The satisfaction of customers' expectations, create wealth for $\mathrm{CN}$ members giving value for both parties, according to a win-win logic. Organizations operate in collaborative networked environments seeking for complementarities that allow them to offer integral and personal experiences around their products and services for a specific customer at any specific time, location and context [19]. Collaboration allows the leverage and rapid configuration of resources as well the possibility for organizations to continually disintegrate and reintegrate themselves in order to quickly respond to customers preferences, providing the basis for agility in dynamic markets [12].

For tourism destinations, increasing request of augmented tourism experience obligates tourism operators to create new and improved services, to adjust them to individual consumer needs and specific interests, to deliver up-to-date information and knowledge sharing systems supporting the self-configuration of tourism packages. Considering that an augmented tourism experience is based on a wide range of heterogeneous aspects (including transportation, accommodation, catering, entertainment, cultural heritage, information systems, knowledge sharing), service providers have to either integrate their resources and organizational systems with others to form networks able to exploit market opportunities. Motivations to establish a $\mathrm{CN}$ among operators of a tourism destination also reside in the business flexibility that such model guarantees to partners in the configuration of an augmented tourism experience. Concentration of each member on core competencies, charging the marketing and information services to a destination manager, strong orientation to tourists' needs, creation of value-adding tourism services are the main competitive advantages of CNs. Competitivity of a CN strictly depends on a correct exploitation of the ICTs which are the enabling factor for a modern $\mathrm{CN}$ rise and development. On the one side, ICTs are a means for coordination and control of $\mathrm{CN}$ activities, interorganizational business process automation, and decisional support. On the other side, ICTs can create an efficient and immediate interface between the destination and the web tourists; they can utilize the information and booking services, made available by the destination manager, for their needs during the 2.0 lifecycle. 
The set of information shared among each service provider and its customers, concerning the context in which information services are used, can be exploited to generate more detailed knowledge about visitors' mobility at the destination. Immediate feedbacks of marketing choices come both from data-mining of tourism experience choices and from social networking analysis activities; they could be used to support destination managers in their decision making processes [20]. Data obtained from all the networked operators can be used to analyze the spatial and temporal behavior of the entire body of subjects in aggregate. The destination manager can analyze and aggregate data coming from each service provider in the $\mathrm{CN}$ to understand the way in which space and time are consumed in order to formulate a more reasoned tourism planning policy aimed to manage the tourist flows in a more rational manner, to relieve the burden from the destination's more congested areas, to encourage tourists to explore other less visited sites or to buy less purchased services. The result would be a more coherent pattern of tourist temporal and spatial activity, which would benefit tourists and the destination as a whole [20].

\section{Operationalizing the Concept of CNs in Tourism: Tourism Breeding Environment and Forms of Collaboration}

From an operational point of view, when some of the tourism service providers decide to reinforce collaboration, they can set stable prescriptive agreements in the forms of Touristic Associations, Syndicates, Touristic Consortia or Touristic Districts, adhering to a base long term cooperation agreement, and adopting common operating principles and infrastructures which constitute the framework of the tourism supply chain. Each agreement characterizes the organizational form of the tourism supply chain in terms of structure of membership, activities, definition of roles of the participants, governance principles and rules. In this study, we name each of such agreements as a Tourism Breeding Environment (TBE) i.e. a Breeding Environment [21] in tourism sector whose members (i.e.: the tourism service providers) share values, culture and infrastructures and have the potential and the will to cooperate in order to pursue the general long-term objectives of territory development and competitiveness.

In a TBE the tourism supply chain control and ownership are distributed among members. They generally appoint the tasks of activities coordination and supply chain management to a Destination Management Organization, DMO, which creates and manages an overall strategic plan for the tourism destination development. It can be a public institution or private organization that aims to promote incoming tourism (territorial marketing) selling composite packages of hotel accommodation, excursion tickets, and other services.. According to Fabricius et al. [22], focus of the DMO is to look inward and towards destination to ensure the quality of the visitors stay while its fundamental task is to create a sustainable breeding environment on which the marketing of the destination and the delivery of the experience are dependent. $A$ strong DMO will be necessary to provide the leadership and to drive and co-ordinate this process. Creating the right environment includes: planning and infrastructure, human resources development, product development, technology and systems development, related industries and procurement. Besides its strategic planning and 
control tasks, the DMO is charged to manage the operational flows related to the service delivery on the ground. This means that the DMO ensures the quality of every aspect of the visitor's experience once they arrive at the destination.

Members of a TBE compete with the others and with players outside the TBE in searching for new business opportunities in the global market. When a business opportunity is identified, a subset of the TBE members can be rapidly selected to become part of a short term Collaborative Networked Organizations, CNOs, oriented to catch the opportunity [12]. Scholars analyzed several cases of such kinds of CNOs in the tourism sectors. Akoumianakis [23] uses the term cross-organizational virtual alliances, referring to the affiliation of partners in collaborative product development (dynamic packaging) in tourism sector [24], strategic business network in cruisetourism sector [25] virtual tourism business system [26].

Although characterized by different contexts, development paths and, also, terminologies, we can cluster classify the different instantiations of CNOs in tourism in only two kinds of short term CNOs that are most evident in a TBE:

Tourism Extended Enterprise (TEE): it refers to a tourism operator that "extends" its business boundaries by involving all or some of its suppliers in the product packaging and delivery in order to offer customers possibilities to a more complete tourism experience. For example, a TEE can be formed by a hotel that stipulates commercial agreements with restaurants, lidos, amusement parks, cruise ship companies. Tourist perceives the overall TEE offer as a whole and, typically, purchase it directly at the hotel (web) site.

Tourism Virtual Organization (TVO): It represents a temporary alliance of private and public organizations that come together to share skills or core competencies and resources in order to better respond to business opportunities, and whose collaboration is supported by computer networks. A TVO is established in a short time to respond to a competitive market opportunity; it has a short life cycle dissolving when the short-term purpose of the TVO is accomplished [27]. New trends in tourism sector demonstrate a growing interest for customers towards the selfcreation of personalized tourism packages. Availability of systems for tourism packaging enable tourist to (self) compose a personalized tourism product choosing a subset of services provided by TBE members (e.g.: 2 nights in the hotel A, 1 night in the hotel B, 2 meals in the restaurants C, 1 ticket for a football match, etc.). Members of the TVO collaborate in order to respond to a market opportunity provided by the tourist and they will work together until their short-term purpose is accomplished.

\section{Conclusions}

The importance of a distributed and efficient supply chain management for a tourism destination is related both to the possibility to give sustainable development to the destinations, in the effort to overcome limits of touristic organization's size and reach economy of scale and competitiveness in contrast to big players; and to the necessity to answer to the request of personalized tourism offer, in line with the new demand trends. Many case studied confirmed that a common planning of networked organizational models and ICT supporting solutions make possible the operationalization of the collaboration concept in the tourism sector and the setting up 
of CNs in a TBE. In this paper we further motivated the adoption of $\mathrm{CN}$ models for a tourism destination highlighting how globalization and ICT evolution made much more efficient and timely the way both of being a tourist (introducing the tourist 2.0 life cycle and the augmented tourism experience concepts) and to manage, coordinate and control activities of networked organizations.

\section{References}

1. Massidda, C., Mattana, P.: A SVECM Analysis of the Relationship between International Tourism Arrivals, GDP and Trade in Italy. Journal of Travel Research 52(1), 93-105 (2013)

2. Papatheodorou, A., Rosselló, J., Xiao, H.: Global Economic Crisis and Tourism: Consequences and Perspectives. Journal of Travel Research 49, 39-45 (2010)

3. Ammirato, S., Felicetti, A.: The Agritourism as a means of sustainable development for rural communities: a research from the field. The International Journal of Interdisciplinary Environmental Studies (2014)

4. Ammirato, S., Felicetti, A.M.: The potential of Agritourism in revitalizing rural communities: some empirical results. In: Camarinha-Matos, L.M., Scherer, R.J. (eds.) PRO-VE 2013. IFIP AICT, vol. 408, pp. 489-497. Springer, Heidelberg (2013)

5. Ammirato, S., Felicetti, A.M.: Tourism Breeding Environment: Forms and levels of collaboration in the tourism sector. In: Camarinha-Matos, L.M., Scherer, R.J. (eds.) PROVE 2013. IFIP AICT, vol. 408, pp. 517-524. Springer, Heidelberg (2013)

6. Volpentesta, A., Ammirato, S., Della Gala, M.: Classifying short agrifood supply chains under a knowledge and social learning perspective. Rural Society 22(3) (2014)

7. Sofo, F., Ammirato, S., Berzins, M.: Leadership as a Process to Create Organizational Culture and Group Learning. International Journal of Knowledge, Culture, and Change in Organizations 12(1), 71-84 (2013)

8. Volpentesta, A.P., Ammirato, S.: A collaborative network model for agrifood transactions on regional base. In: Lytras, M.D., Ordonez de Pablos, P., Ziderman, A., Roulstone, A., Maurer, H., Imber, J.B. (eds.) WSKS 2010, Part II. CCIS, vol. 112, pp. 319-325. Springer, Heidelberg (2010)

9. Volpentesta, A.P., Ammirato, S., Della Gala, M.: Knowledge exchange and social learning opportunities in direct agri-food chains. In: Camarinha-Matos, L.M., Xu, L., Afsarmanesh, H. (eds.) PRO-VE 2012. IFIP AICT, vol. 380, pp. 340-348. Springer, Heidelberg (2012)

10. Dunn Ross, E., Iso-Ahola, S.: Sightseeing tourists' motivation and satisfaction. Annals of Tourism Research 18(2), 226-237 (1991)

11. Buckley, R.: Framework for ecotourism. Annals of Tourism Research 21(3), 661-669 (1994)

12. Camarinha-Matos, L.M., Afsarmanesh, H.: Collaborative Networks: Value Creation in a Knowledge Society. In: Wang, K., Kovacs, G., Wozny, M., Fang, M. (eds.) Knowledge Enterprise: Intelligent Strategies in Product Design, Manufacturing, and Management. IFIP, vol. 207, pp. 26-40. Springer, Boston (2006)

13. Volpentesta, A., Ammirato, S.: Alternative Agrifood Networks in a regional area: a case study. The International Journal of Computer Integrated Manufacturing, Special Issue on "Collaborative Networks as Modern Industrial Organizations: Real Case Studies" 26(1-2), 55-66 (2013) 
14. Wanga, Y., Fesenmaier, D.R.: Collaborative destination marketing: A case study of Elkhart county, Indiana. Tourism Management 28, 863-875 (2007)

15. Gilbert, D.C.: An Examination of the Consumer Behavior Process Related to Tourism. Progress in Tourism, Recreation and Hospitality Management 3, 78-105 (1991)

16. Swarbrooke, J., Horner, S.: Consumer behaviour in tourism. Butterworth-Heinemann, Oxford (2007)

17. Jennings, G.: Perspectives on Quality Tourism Experience. In: Quality Tourism Experiences, pp. 1-15. Elsevier Butterworth-Heinemann, Oxford (2006)

18. Karanasios, S., Burgess, S., Sellitto, C.: A classification of mobile tourism applications. In: Global Hospitality and Tourism Management Technologies, pp. 165-177. IGI Global (2011)

19. Romero, D., Molina, A.: Collaborative Networked Organisations and Customer Communities: Value Co-Creation and Co-Innovation in the Networking Era. Journal of Production Planning \& Control, Special Issue on "Co-Innovation and Collaborative Networks" 22(4) (2011)

20. Shoval, N.: Tracking technologies and urban analysis. Cities 25(1), 21-28 (2008)

21. Loss, L., Crave, S.: Tourism Breeding Environment: Business Processes Applied to Collaborative Networks in Tourism and Entertainment Sector. In: Camarinha-Matos, L.M., Pereira-Klen, A., Afsarmanesh, H. (eds.) PRO-VE 2011. IFIP AICT, vol. 362, pp. 197204. Springer, Heidelberg (2011)

22. Fabricius, M., Carter, R., Standford, D.: A practical guide to tourism destination management. World Tourism Organization, Madrid (2007)

23. Akoumianakis, D.: Ambient affiliates in virtual cross-organizational tourism alliances: A case study of collaborative new product development. Computers in Human Behavior 30, 773-786 (2014)

24. Novelli, M., Schmitz, B., Spencer, T.: Networks, clusters and innovation in tourism: A UK experience. Tourism Management 27, 1141-1152 (2006)

25. Lemmetyinen, A.: The Coordination of Cooperation in Strategic Business Networks - the Cruise Baltic Case. Scandinavian Journal of Hospitality and Tourism 9(4), 366-386 (2009)

26. Hopeniene, R., Railiene, G., Kazlauskiene, E.: Emergence of Virtual Tourism Business System: empirical findings. Economics \& Management 14 (2009)

27. Camarinha-Matos, L., Afsarmanesh, H.: Collaborative Networks: Reference Modeling. Springer, New York (2008)

28. Mills, J., Law, R.: Handbook of consumer behavior, tourism and the Internet. Haworth Hospitality Press, New York (2004)

29. Stamboulis, Y., Skayannis, P.: Innovation strategies and technology for experience-based tourism. Tourism Management 24, 35-43 (2003) 